\title{
Cross-Cultural Management New Model: Epistemological Reviewing and New Variables
}

\author{
Elgouchi Awatif \\ Mohammed V University of Rabat, Morocco
}

\begin{abstract}
This study aims to revise and complete Hofstede and Trompenaars' theories developing new methodological rules and new variables according to non-western cultures. We propose a model in a culturalist approach that goes beyond the descriptive taxonomy of cultures to the study of specific dynamics generated by their encounter in workplace. Our goal is to construct a theory outline that reflects the importance of these dynamics in their impact on organizational behaviour and work performance. We verified the validity of our model by putting it to the test of the functioning analysis of multicultural teams working in foreign companies based in Morocco and the identification of logics that occurs in. Using new variables, we show that the spiritual dimension of work plays a key role in the way to conceive and achieve it. This has an impact on motivation methods and professional accomplishment. Furthermore, we demonstrate that the degree of openness predisposes a culture more than another to acquire intercultural skills in business and to more easily adopt new working methods. Our findings contribute to give more intelligibility both to diversity managers and cross-cultural management researchers.
\end{abstract}

Keywords: National Culture, International Competitiveness of Firms, Identity in Work, Hofstede, Trompenaars.

\section{Introduction}

A first exploratory and descriptive research, within multicultural teams operating in Morocco, allowed us to notice that by applying the cultural variables of Hofstede (1997 and 2010) and Trompenaars (1993 and 2004), some aspects of culture escaped the study, including the attitude of participants facing otherness and the philosophical and spiritual conception of work as a human particularity. Indeed, intercultural management, founded mainly by North American and Western European theorists, identifies cultural differences in the workplace through supposedly limited and universal variables. They would be characteristic of all the differences that are likely to exist between cultures. However, such certainty betrays a defective attitude towards human diversity and a restrictive scientific posture. 
How can we easily admit that the study of the relation to time, space, power, group, risk is enough to know fully and thoroughly all characteristics of one culture and be able to compare it to another? According to what postulate can we say that these dimensions are limited and mechanically transferable without any nuance?

In addition, intercultural management is defined as the meeting with "the other" in the organizational context. Therefore, its object of study must go beyond the descriptive taxonomy of cultures to the study of the particular dynamics generated by their encounters. So, it is not a question of defining only what is constant in a culture (d'Iribarne, 1989) but also and above all identifying what is likely to change. It is not enough to do the "radiography" of cultures (Hofstede \& Bollinger, 1987) but to understand the dynamics created by their meeting. Some cultures may appear closer on some variables in particular, others may be more conciliated than their respective geographical situations or historical experiences suggest.

As a result, the variables we propose are the expression of the different sides of this dynamic which precise knowledge will enable the global manager to prevent blockages on the one hand and to initiate appropriate synergies on the other hand. Being aware of convergence and divergence points between the different cultural actors in action makes it possible to create intercultural synergies (Adler, 2008).

With intensified internationalisation of business, little has been done to document the crosscultural issues in an Arab country like Morocco. To rectify this situation, the research described in this paper aimed to explore the impact of national culture on organizational behaviour and the intercultural dynamics between Moroccan employees and expatriates from different cultures. This involved an empirical study using the questionnaire survey and the interview, derived from critical reading of culture dimensions from Hofstede (1997) and Trompenaars and Hampden-Turner (2004).

\section{Methods}

\subsection{The basis of new methodology}

\subsubsection{The historical approach}

While management theorists, adepts of the Western ethnological vision, consider that cultures differ in the way they respond to problems, it is first necessary to admit that they don't have the same perception of these problems nor the same interest. In fact, cultures prioritize problems and needs and it is partly for this reason that they do not provide the same answers. 
Their historical experiences being different, there is indeed a need to seek, in this series of strategies, both free and constrained, this source of cultural responses. They have been discovered or invented over the centuries and then invalidated, confirmed or transformed. Knowledge of the conditions under which the actors of a culture were able to develop their strategies allows us to understand and explain in depth the choices they made about this or that cultural response; choices that they were able to maintain or modify later. All this constitutes different paths that produce different cultures. For the intercultural researcher, it is just as important to study the difference in orientation and action choices, in a strategic approach, as to know cultures, in a diachronic approach, from their historical origins, their traditions, their constraints and interactive liberties.

However, none of the intercultural management theorists considered it important to inform the analysis of the variables for each culture with a historical dimension. Only D'Iribarne, in his Logique de l'honneur, has tried to explain the difference between the managerial styles of the French, Dutch and American cultures in their respective histories and traditions. It is regrettable that the study does not result in a tool for analysing cultural difference but only in a descriptive comparison of three different styles.

Thus, a first requirement that both the researcher and the manager must set for themselves is to understand the historical and social context they are dealing with. Such research would provide a correct and complete understanding. On a more practical level, it would also have given the opportunity to conceive other ways - because they would have been understood - of responding to common organizational problems. For the global manager, it would be a treasure trove of possibilities and verified achievements that could moreover help him in designing the type and degree of change to lead within his team. For this study, cultural variables are explained through a religious, traditional, political, economic and informational retrospective.

\subsubsection{Reconciling the quantitative and the qualitative}

Since the 2000s, an emerging generation of intercultural researchers has been attacking the methods of Hofstede and Trompenaars. The adepts of participating observation such as Chevrier (2003), Cazal (2000), Aktouf (2006) follow in the footsteps of their precursor d'Iribarne and praise the advantages of qualitative investigation based on ethnographic and semiological methods. They criticize the canonical model, which is still dominant, for its excessive use of quantitative methods. Certainly, a lot of information does not always lead to more knowledge about intercultural issues. However, significance and representativeness remain two sine qua non conditions to go beyond the case study and lead to a reliable and generalizable analytical model. 
To do this, it is not pointless to provide for a less sectarian method. In this study, the use of the questionnaire made it possible to reach a large sample of respondents and different sectors, the role of the interview was to complete and verify the reading of the qualitative data that were collected.

\subsubsection{The organizational anchoring}

It is clear that the questions must follow strict rules if the answers they require are to produce reliable and usable data. In addition, the fundamental bases for developing any questionnaire remain the research objectives and the elements contained in the hypotheses.

When reading the databases provided by Hofstede and Trompenaars, we were confronted with some shortcomings in the presentation of some situations taken out of their organizational context, which increased the confusion of answers that, even if they were sincere, could not be reintroduced and applied to the organizational field. For example, the notion of the group changes significantly in content and importance, whether it is family, friends, co-workers or compatriots. Asking a question about an individual's commitment to family and friends cannot be transposed to the world of work as a clue. Here, it is necessary that the cultural element be put back in its place. Thus, the researcher who is involved in the sociology of organizations is called upon to mobilize more than one discipline, to draw extensively on anthropology, psychology and history, to understand the cultural fact in the workplace. But the formulation of the questions and the situations proposed to the respondents cannot be outside the particular context of the firm, even if their preparation and reading require multidisciplinary insights. Authors such as Hofstede and d'Iribarne refer to these areas only to support a point of view, sometimes preconceived, or to justify a generalization at the end of a chapter. However, the opposite approach must be adopted.

Indicative situations must therefore remain within the organizational context. This is possible by applying all the cultural variables identified to areas directly related to the management of the organization such as motivation, evaluation, decision making, leadership, etc. In addition, they must only target a population that is confronted and concerned by intercultural issues in the workplace (some of the respondents to the Hofstede survey were MBA students). Only to this extent would the research and its results be contingent on the field of study.

\subsection{Data}

\subsubsection{Questionnaire}

We have asked all the questions that we think are relevant and will allow us to see the impact of a particular cultural variable on a specific aspect of organizational behaviour. 
Some questions were asked exclusively to local managers and staff, others exclusively to foreign managers and expatriates, especially to identify perceptions on both sides but also to adapt the questions to their respective status in the company. In the presentation of the questions, it was important to modify the sequence of the questions in order not to reveal the researcher's intentions and to ensure that the answers were more spontaneous.

As for the interview guide, we developed it as comments and questions were raised about some of the results of the questionnaires. Semi-directive interviews (15 in total), conducted subsequently with company executives and managers, allowed us to verify some specific points or complete some conclusions.

\subsubsection{Research population sample}

Assessing the impact of Moroccan culture on the organizational behaviour of its actors requires the questioning of all employees of multinationals, all trades and functions combined. Respondents therefore belong to all hierarchical levels of the company. However, it was necessary to require an adequate level of education to understand the questions asked.

The total sample of the study includes $48 \%$ managers - 37\% of whom are Moroccan - and 52\% of employees $-34.5 \%$ of whom are foreign -. Of sixty-four companies contacted, only thirteen agreed to participate in the survey. They belong to different management schools and operate in different sectors: AkzoNobel - Bayer - Canal Sur Television - Ericsson - Fruit of the Loom - Nokia Corporation - Sanofi-Aventis - SNCF - Sofitel - Tecmed - Thales - TVE - ZTE Corporation. The cultures represented are: Morocco, France, China, the Netherlands, Spain, Germany, Sweden, Canada, India, the United Kingdom, Poland, and Cameroon.

\section{Results}

The results presented here are the outcome of 167 questionnaires and subsequent 15 interviews with some executives and managers of the same companies to shed light on certain results that seemed contradictory or incomplete.

The methodological protocol followed in the data analysis is based on four main steps:

- A descriptive analysis of the cultural particularities of the Moroccan employee in a multicultural situation,

- A comparative analysis with the salient cultural features of the other cultures represented,

- An analysis of the intercultural dynamics between Moroccan culture and the other cultures represented,

- Recommendations to prevent blockages and enhance synergies 


\subsection{Individualism/collectivism}

The individualism/collectivism variable, used here, is derived from Hofstede's but deals with the relationship between the individual and the group only in the professional context and through several aspects such as the degree of individual independence, the importance given to objectives and self-realization, which Hofstede calls "masculinity"; or through the predominance of laws between individuals at the expense of the relationships which Trompenaars calls "universalism". Other indicators such as the preference for collective work and evaluation, the predisposition to sacrifice for the group, the importance of conviviality practices in the professional sphere are also prolific in terms of meaning.

We define this variable as a set of shared values that govern the individual's relationship with the group. It includes the tendency towards collective work, the predisposition to sacrifice for the group, the preference for evaluation and collective responsibility, the degree of conviviality practices at the workplace and the importance of achieving objectives at the expense of human relationships.

All cultures are for collective work but not for all its implications. Local staff is the most consistent with their choice of group work. He is the most willing to sacrifice his interests in the company for the group (60\% of Moroccans against $27 \%$ of Spanish and $14 \%$ of British) and would be close, on this issue, to the Indian vision (66\%); he differs from all cultures represented by a preference for collective evaluation in the case of collective work (74\% of Moroccans against $16 \%$ of Indian and $14 \%$ of British); he agrees with the Indian point of view for collective responsibility in the case of failure (77\% for Moroccans against $83 \%$ of Indian). These data are important for managers who want to mobilize their teams around a stimulating and ambitious project. It is easier to provide for a collective evaluation than to reward efforts separately. On the other hand, it is more complicated and even inadvisable to try to define individual responsibilities in case of failure. The manager must be able to recognize and correct errors without designating a "guilty" person. Moreover, such a collectivist trend makes it easier to manage diversity because it is easier to create support around a common identity and to obtain loyal and effective behaviour from employees.

Moreover, for local staff, the achievement of common objectives necessarily requires a quality of social cohesion in all its aspects; it is therefore essential to multiply opportunities for the creation of relational synergies and to raise expatriates' awareness of the importance of the human dimension in professional life. 
Finally, locals pay more attention to free time and to the family making work a means and not an end. In this regard, they are in line with Chinese culture. Certainly, work represents a primordial and constitutive activity of self-esteem, but it remains at the service of social life and cannot fully justify the existence of the individual. Performance policies must take this particularity into account and consider that it is more effective to get "the best" rather than "the maximum" from employees.

\subsection{Relationship to power}

The variable we propose to address this question is more global than the one previously developed in the theories of intercultural management; it deals not only with the distance tolerated from the hierarchy (Hofstede, 1997) but also with the aspects that are recognized as a source of power (Trompenaars, 1993), the need for freedom and alternative to rules and directives, presented by Hofstede as "uncertainty avoidance", the part of the private and professional in the relationship to the hierarchy, named by Trompenaars "the specific/diffuse" involvement, the styles of leadership tolerated in the company as well as the patterns of decision making.

To understand the relationship to power in a culture and, consequently, within the company, it is necessary to know its sources, the reasons that make it legitimate. Trompenaars explains this first dimension of power in what he calls the foundations of social status. We retain five sources of power: achievement, function, age, gender and social status.

Second, the styles of leadership tolerated in an organization are only an expression of the need for freedom, responsibility and creativity that Hofstede calls "uncertainty avoidance". In companies, individuals who do not have the anxiety of uncertainty and risk, whatever the origin of their "serenity", feel the need to act with total freedom when they decide and in the way they feel most appropriate. They are less accepting of the rules and limits imposed by a hierarchy. Conversely, individuals who do not tolerate ambiguous and high-risk situations recognize the importance of guidance, laws and rules. They readily accept the protective power of the line manager.

Finally, in the relationship between hierarchy and subordinates, the choice is made for the part of the private that we want to share in the professional situation. Trompenaars explains this trend in a dimension that he describes as involvement in the relationship with others, the two opposites of which are the specific way of sharing with others a single aspect of oneself particularly professional - or, on the contrary, the diffuse approach of engaging all facets of one's life at the same time. 
For local staff, the first sources of power are achievement and function, which means that status must be conferred according to pragmatic and rational considerations. From this point of view, it is closer to French staff and moves away, for example, from the Chinese and Indian vision.

Moreover, even if local staff expresses a strong need for more decision-making freedom and alternatives in the exercise of their functions in relation to corporate directives (85.4\%), respect for hierarchy on the part of local staff seems to be a general rule in most companies $(78 \%$ of expatriate managers, from all nationalities, say that they are never or rarely forced to remind Moroccan employees of their position in the company). Thus, it is not difficult for expatriates to establish their authority. However, managers as well as the parent-company would benefit more from considering their local subordinates as on-site partners who would better inform their decisions. The manager's role in this case would be to communicate and ensure that the needs and views of his local teams are respected during the development of strategies at headquarters level.

Finally, in this subordinate/superior relationship, there is a demand for more social and informal links in the professional context (33\% of Moroccan staff claim more informal activities), particularly with expatriates (55\%), which corresponds to the highly collectivist aspect developed above.

\subsection{Degree of affectivity}

This variable broadly follows Trompenaars' "neutral/emotional" dimension but applies to specific aspects of management. In each culture, a more or less important part is given to the affective in the face of rationality. The degree of emotion that is externalized in the relationship with others is often the result of a convention. Some cultures willingly show their feelings about an event or situation and their reaction is very emotional. Others prefer to control their affect and adopt a neutral attitude. This does not mean that they are devoid of feelings; joy or grief reached an intense level and can no longer be controlled, they will also be externalized. It should be noted that an individual with a high degree of affectivity expects his or her feelings to be recognized and would feel frustrated and disappointed by a neutral or rational attitude; on the other hand, an individual with a low degree of affectivity expects an objective reaction and would feel offended and attacked by a high degree of affectivity. Of course, in companies, these two attitudes have a deep influence on communication styles, conflict management and how to react to leadership.

The majority of participants, of all nationalities, seem willing to express themselves openly and show a high degree of affectivity in a situation they consider important to them. The difference lies in the nature of the situations considered as such. For local staff, priority is given to conflict situations based on respect for values (56.6\%) and then to relationships (26.7\%). It is in these types of situations that locals can easily show their emotions or miscontrol their feelings. On 
the other hand, for the rest of the cultures represented, situations related to the achievement of objectives or conflict situations are a major issue and can make them more emotional than neutral. These two different attitudes towards situations related to goal achievement explain the fact that $76 \%$ of expatriates see a large part of unsaid in the communication of premises. This is because they avoid direct expression and confrontation less when it comes to relationships and values than when it comes to defending ideas and projects, especially in the presence of a superior. The manager must show more insistence to gather the opinions of his employees and avoid any direct attitude that would be considered as a personal attack.

\subsection{The material and the spiritual}

The religious tends to disappear in so called secularized Western societies. This idea, quickly accepted by social sciences subjected to rationalist thinking, does not take into account symbolic phenomena in the analysis and theorization of individual behaviour. For a long time, researchers in management sciences, like managers, have been silent about the spiritual dimension in the workplace, the last few decades having established a "secular" and "neutral" management that did not think of religion or even religion. Today, seeing the number of books and articles recently published on the religious in workplace (Demontrond, 2007; Barthe, 2012), one would believe that there is finally an awareness of the influence and importance of religious in relation to economic issues. However, reading these works shows that they offer only a semblance of an answer, that they are only a hasty reaction to a number of news item and anecdotes pointed out since the events of September 11 and the Western war against the ghosts of immigration and terrorism. Litigation around the wearing of the Islamic veil, the growth of specific markets for halal or kosher products, debate on Sunday work, development of Islamic finance are all topical issues that we are now trying to link to management. However, the presence of the sacred in business and its real influence on organizational behaviour does not lie as much in the external aspects of religious practice as in the deep values it suggests (Touba, 2006). Thus, we distinguish between spiritualist cultures and materialist cultures.

In spiritualist cultures, a considerable part of cultural values comes from religious beliefs. These guide ideological preferences, largely predetermine political systems and relationships with others. In business, they redefine the meaning of performance that goes beyond the tangible result towards an allegorical value: contribution to human work, service to the religious community, divine recognition, gratification for what is considered a good deed, meaning to existence, etc. On the other hand, they give a stronger symbolic meaning to self-realization through the enhancement of action. 
The historical and politico-economic experience of materialist cultures has meant that values of philosophical and scientific origin have taken on a more important place than those of religious origin. Political systems are based on the notion of gain and profit, a pragmatic sense prevails in relationships and work takes on a utilitarian value and guarantees freedom and equality. Within the company, performance is focused only on measurable objectives. Interpersonal relationships therefore have no reason to exist other than to pursue common objectives. Individual achievement is highly valued and corresponds to the material and moral recognition of competence. On one hand, work is the ongoing link to the community and to the divine and, on the other hand, it only obtains the value of the result produced. The meeting of these two divergent visions of the productive act is likely to create a serious uneasiness. Thus, spiritualists may feel frustrated by the lack of sacred elevation of materialists at work. They seem too pragmatic or even opportunistic; their concern for productivism makes them "less humane" because their action has only a capitalist value. For their part, materialists can be annoyed by the attitude of these cluttered utopians and slowed down by the weight of their beliefs.

We notice in the cross-cultural field a denial of the spirituality presence. There is a belief that the company can be a non-religious space and there is a desire for neutrality to the point of making it a taboo. Thus, for $59 \%$ of the premises, it is unacceptable to ask for the religious confession of an employee in the company. The percentage of people who do not mention the issue of religious denomination increases significantly for English (100\%), Spanish (91\%), Indian (83\%) and French (73\%) participants. Chinese participants seem more comfortable with this aspect in the company since $80 \%$ of them do not mind learning about their employees' beliefs.

People who do not accept the question of religious confession in the workplace justify their answer by converging categories: thus, $56 \%$ of them think that it is a question of "personal freedom" and "freedom of worship", 27\% consider that religion "has no impact on work" or "performance" and that "it does not fit into professional skills", the rest of the answers describe the question as "indiscreet" which can lead to "discriminatory" acts.

It is than considered that "work has no religion" and that the company does not have to take care of the spiritual life of its employees. Such an attitude seems paradoxical, if only on the practical level of celebrations and public holidays based on Christian, Jewish or Muslim calendars. Looking more closely at the link between work and religion, we see that the impact is greater than we are willing to admit. 
Thus, a first question on secularism shows considerable attachment among locals to the state's religious system. Unlike all other nationalities represented, $77 \%$ of locals declare themselves against the secular system, which means that religion for them is an integral part of a public and affirmed identity, with all that this implies in terms of common values and practices.

At the organizational level, this attachment to spirituality is also important since the religious stands out behind the different motivations and decisions related to work. Thus, $59 \%$ of locals think, from time to time or often, about applying and respecting their religious values during the exercise of their work, $17 \%$ always think about it.

The religious factor also guides the definition of global objectives related to the career and professional life of the local people, $82 \%$ of them take religion into consideration in determining their interests within the company. Chinese staff is close to this result $(60 \%)$.

In referring to the more apparent aspect of spiritual life, namely religious practice, we notice that the percentages are minimal, once again, among expatriates who consider that religious practice is not a daily necessity and is not part of the organizational space. On the other hand, more than $86 \%$ of locals express the need to have the opportunity to practice their religion in the professional environment. Chinese staff also reports a similar percentage in this respect $(60 \%)$.

\subsection{Openness degree}

Cultures evolve by opening up to others. History has confirmed this several times. They are designed as closed systems: they protect themselves, and open: they need information and interaction to survive. In this regard, culture is essentially dynamic; it corresponds to what community members do and believe they are. More fundamentally, culture will be said to represent the work a community does on itself to exist and reproduce itself as a social entity, to maintain and change itself; ultimately, it is the creation and recreation of a world. This implies that the intelligibility of any cultural system must be found not only in the system itself but also in its interaction with other systems, and that this interaction is not only a simple dependence or constraint, it is a fundamental part of the system itself.

Culture is also the matrix of identity. It is built around a "hard core" of cultural elements considered as immutable, including assumptions and values (Rokeach, 1973; Schwartz, 1987, 2005) and cultural elements that can be transformed or abandoned, namely norms or some values that are considered as secondary. As a result, we believe that the degree of one culture change in contact with another can be a meaningful analytical variable. It is a question of defining cultures by their ability to adapt their values in contact with another value system. 
Historical and social conditions make that some cultures, at some point in their "life", become more or less willing than others to change. The trials of war, colonization, underdevelopment or "overdevelopment" lead to a rethinking of identity that makes cultures more resistant to the benefits of other cultural models. This general atmosphere even affects the individual attitude of social actors who begin to look suspiciously at any proposal for new visions that come "from elsewhere". Some particular social structures influence the attitude of openness to other cultures. A young society includes a large category of individuals with "more diluted" cultural features; this mainly concerns Internet and satellite-channel generations where the choice of values itself is not only made in reference to the elders but to a global palette available on websites and TV programs. Finally, some cultures have a heterogeneous subcultural composition and are able to easily accept and integrate other practices or ways of doing things on an ad hoc or permanent basis as long as they serve the intended goals and do not oppose their core values too much.

Thus, cultures with a high degree of openness are built around a restricted "hard core" that allows a great interaction with everything that represents a novelty. They more easily welcome and adopt rules, attitudes and ideas and can generate them themselves. Cultures with a low degree of openness define their identity through a quite large "hard core", made up of deep values that make them impermeable to any novelty. The assimilation of different ideas and rules is a laborious process - even impossible - which risks leading to conflicting tension and identity withdrawal (Bataille, 1997). Of course, not every culture can be totally open or totally closed, the difference lies in the part of identity that it willingly submits to change.

All the theories of cross-cultural management have omitted this aspect of their studies. Hofstede unintentionally mentioned an angle with the "uncertainty avoidance" dimension, which refers to the feeling of anxiety about the unknown future. The dimension we propose concerns a more or less great anxiety about one's own identity. The first is only one of the second's results.

However, the relationship between culture and change is one of the most decisive issues in cross-cultural management, which aims to bring different ways of doing and acting into line with one's own vision. Within the company, individuals belonging to an open culture have a high tolerance for stress and changes in working methods and conditions. They are curious and enthusiastic about partners from different cultures and are committed to getting to know and integrate them. Conversely, individuals from a closed culture are very anxious about new developments and have difficulty tolerating change in the workplace. They cling to their methods, old or new, and do not accept any criticism or questioning. Their attitude - displayed or hidden - towards other working-methods varies between disinterest, irony or condescension. 
The question on uncertainty does not reveal a particularly anxious attitude on the part of local staff $(26 \%)$. Hofstede attributes, in his study, to the Arab countries a rather fearful attitude towards the unknown, states that this attitude is reflected in a permanent search for everything that is stable, predictable and explicable (Hofstede, 1993, p.113). Changes and conflicts are perceived as a threat that must be avoided by setting up very detailed rules and procedures. However, the answers we obtained for the need of decision-making and alternative within the company ( $85.4 \%$ of locals) demonstrate, on the contrary, a desire to act in freedom to better face the unexpected. Local staff often considers the parent company's policies as cumbersome and disabling, or poorly adapted.

Another aspect of the degree of openness is the interest that cultural actors have in foreign cultures. The willingness to learn about others and the ability to borrow complementary ideas and lifestyles represent a true cultural intelligence. Apart from Indian expatriates (16.7\%), all consider it important to learn about each other's culture, mainly through the media and testimonies of experiences ( $76.8 \%$ of locals, $66 \%$ of French, $80 \%$ of Chinese, $72.7 \%$ of Spanish, $100 \%$ for others).

Priorities in a changing situation are clearly different between local and expatriate staff. For locals, by far the most difficult thing to change remains religious values; only $5 \%$ are willing to change values related to their beliefs in order to succeed in a professional project. The family comes second (17\%). For English, Spanish and French staff, the priority is undoubtedly for the family $(0 \%, 9 \%$ and $17 \%$ respectively). Second, importance is given to work-related values (14\%, $18 \%$ and $33 \%$ respectively). Chinese staff also gives great importance to family (20\%), followed to a lesser extent by the work team (40\%). Finally, Indian staff give full priority to work-related values (17\%), followed with an equal percentage by traditions, family and religion $(33 \%)$.

\subsection{Relation to time}

This is one of the constant variables in the analysis of cultural differences in companies. Time is a decisive element in the design and achievement of objectives and a key factor in the success of projects.

The first question on the importance of the past, present and future in the lives of respondants does not reveal salient features, unlike the results developed in the studies of Trompenaars or Kluckhohn and Strodtbeck, which distinguish cultures oriented towards the past - resistant to change -, cultures focused on the present - for which immediate gain and pleasure is most important -, and cultures projected towards the future - which work for economic and social development-. 
All the cultures represented here give priority to the present (53\% of Moroccans, $72 \%$ of French, $71 \%$ of English, $60 \%$ of Chinese, $80 \%$ of Indians), followed by the future ( $44 \%$ of Moroccans, 27\% of French, 28\% of English, 20\% of Chinese, 20\% of Indians). The past comes last.

The local staff, although they belong to one of the most traditionalist cultures according to Hofstede, is the only one to attach almost equal importance to both present and future. This conception certainly has an influence on the motivation of the staff and on the way to manage their careers, since the future represents a major challenge.

Another way of considering time was explained by Hall (1983), and followed by Trompenaars, who distinguished monochrone time and polychrone time. We asked two questions to identify the way participants manage time. The first question shows a high preference among local staff for performing several tasks at once (58.5\%). On this issue, Chinese staff (59\%) is approaching Moroccan staff; for both of them, the proof of efficiency is not to go in a straight line between $\mathrm{A}$ and $\mathrm{B}$ with minimum of effort but to go in several lines at the same time between several A and B. For the second question on meeting deadlines versus quality, 100\% of English, Canadian, Polish and Spanish staff attaches great importance to meeting deadlines, while other cultures seem more concerned about quality of the work done, even if it means finishing it after the time set (73\% of Moroccans, 55\% of French, $60 \%$ of Chinese).

\subsection{Relation to space}

The last cultural variable we will examine concerns the relationship and role we reserve to the environment. The attitude towards nature is an indicator of our daily behaviour in the company and the way we manage business. A culture may seek to control nature, submit to it or live in harmony with it. In companies, this has an impact on space management, proxemics and ergonomics.

In response to the question on man's relationship with nature, most respondents consider that man is not the master of it, that he must adapt to the requirements of his environment because he is part of it. Whatever the source and dimension - religious, ecological, philosophical, etc. of such a conviction, it seems generalized for all cultures but to varying degrees. It is far more entrenched among Indian and Moroccan participants, with $100 \%$ and $85 \%$ respectively. At the same time, we asked an indirect question to check whether the participants' answers were not just an echo of the new discourse perpetuated by the media on ecological awareness and respect for nature. Thus, the answers to the question on the use of Moroccan raw materials contradict the initial results and confirm our assumption; the opinions in favor of increasing use of Moroccan natural resources are much more numerous, even among Indian participants $(60 \%$ of Indians, $60 \%$ of Chinese, $67 \%$ of French, $90 \%$ of Spanish). It is indeed difficult to combine 
ecological awareness with ever-increasing needs for consumption and comfort. In modern life, development goes hand in hand with the maximum optimization of natural resources.

Finally, within the company, it appears that the taste for open space is over among Spanish $(64 \%)$ and British (57\%) expatriates, followed by the Chinese (40\%) and French (39\%) who clearly express their preference for working in an individual space. Only Indian staff, followed by Moroccan, still appreciates the sharing of the workspace; it is these same cultures that have defined, above, their belonging to nature as an integral part.

\section{Conclusion and discussion}

We tried to answer the following main question: "How should cross-cultural management be approached in a non-Western context? ». The critical readings of the Hofstede and Trompenaars' theories and the results obtained show the validity of the suggested model on the following basis:

First, successful analysis of cultural impact on organizational behaviour requires the translation of cultural dimensions into real or likely organizational situations : culture does not act in the same way or with the same strength when it comes to the private sphere, the public domain or professional life. In developing data collection tools, the need to share the cultural repository must be combined with the need to observe the specificities of the organizational framework. In our survey, we maintained the index situations in the organizational context by applying cultural variables to areas directly related to organizational management such as motivation, evaluation, decision-making, leadership, etc. By constantly making this link, it was not difficult to read the answers and translate them to reach the reading of the cultural dimensions.

Then, intercultural management must go beyond the descriptive and comparative approach towards a dynamic approach: cultural dimensions allow dynamic analysis of similarities and differences between two cultures within the same company. The aim is to identify the current cultural values that are directly related to organizational behaviour and to identify, on the one hand, their evolving internal dynamics and, on the other hand, their interactional external dynamics. Thus, in the case of our research, we have been able to define the Moroccan cultural aspects that tolerate change and those that constitute deep identity. We were also able to discern the convergences to be reinforced between the Moroccan culture and the other cultures represented and the divergences to be reduced.

Thus, all respondents say they are "collectivist" but it is the Moroccan staff who are the most consistent with the consequences of collective work. For him, the achievement of objectives inevitably requires a quality of social cohesion in the company. 
In its relationship with power, Moroccan staff first recognizes achievements and function, which explains its respect, recognized by all, for the hierarchy despite a great need for freedom of decision-making and alternative to the parent company's policies. A better social bond is also a need and a condition for a better relationship with superiors.

Communication situations concerning respect for values and relationships call for more demonstration of feelings and direct expression among local staff, while other cultures represented are more expressive in situations related to achieving professional goals. This difference explains the indirect communication style noticed by expatriates among Moroccan subordinates.

At the end of the study, it does not seem absolutely essential that the participants should be in perfect resonance to make a project succeed. But if the "multiculturality" of teams encourages the creativity of members, it conceals a great potential for dysfunctions and even blockages. However, intercultural competence, i.e. the ability to see and understand the cultural foundations of other ways of working and to make the most of them for positive intercultural dynamics, is not the priority of multicultural companies, which too often expect their local or expatriate skills to be constantly adapted. However, we can conclude that certain cultures, because of their particular relationship to otherness and their openness to other cultures, are more capable than others of "naturally" having this competence. For other cultures, it is necessary to help develop this skill.

Most multicultural companies do not provide prior training for their expatriates, who are bound by results as soon as they arrive. However, when faced with a way of doing things, it is essential to understand its logics, behaviours, motivations and other particularities with the same neutrality and predisposition to discovery. Under no circumstances should one's judgment be extended to stereotypes fomented by ignorance of the other. It is essential to eliminate misinterpretations that are the first steps in a climate of mistrust and misunderstanding towards the other side. This competence is acquired through continuous learning during any intercultural encounter, but above all through the mastery of methods and techniques of analysis and communication that allow us to situate ourselves in dialogue, to take some distance and to lead the process of exchange.

Finally, the spiritual meaning given to work is a determining factor in organizational behaviour : the results of the survey show that the different cultural meanings given to work as human action have been shaped by spiritual beliefs. In their evolution, some cultures have retained this spiritual charge more than others and have not exchanged it for the capitalist value of modern society. We were able to identify the considerable influence that this dimension can have on organizational behaviour and the need for companies to finally recognize religion as a determining variable for motivation and personal fulfilment, not only in what it has in apparent terms, such as practices, but also and especially in the principles of conduct that it generates. 
Managers have the responsibility to get out of this denial and define a framework for the translation of the religious element into management rules. This step is important enough to be the subject of a separate problematic.

\section{References}

[1] Adler, N. J. and Gundersen, A., (2008). International dimensions of organizational behaviour, Thomson South-Western, USA.

[2] Aktouf, O., (2006). Le management entre tradition et renouvellement, Gaetan Morin, Montréal.

[3] Barthe, I., (2012). Management et religions : décryptage d'un lien indéfectible, EMS, Paris.

[4] Bataille, Ph., (1997). Le racisme au travail, Editions La Découverte et Syros, Paris.

[5] Cazal, D., (2000). « Comparaisons internationales et GRH : intérêt d'une approche en termes de réflexivité », Les cahiers de la recherche, IAE de Lille.

[6] Chevrier, S., (2003). Le management interculturel, PUF.

[7] Demontrond, P. R. and All. (2007). Anthropologie du sacré et sciences de gestion, Editions Apogée.

[8] Hall, E.T., (1983). The Dance of Life, The Other Dimension of Time, Doubleday, New York.

[9] Hofstede, G., (1997 and 2010). Cultures and organizations, Software of the mind, McGrawHill, USA.

[10] Hofstede, G. and Bollinger, D., (1987). Les différences culturelles dans le management, comment chaque pays gère-t-il ses hommes?, Les éditions d'organisation, Paris.

[11] d'Iribarne, Ph., (1989). La logique de l'honneur, gestion des entreprises et traditions nationales, Seuil, Paris.

[12] Klukhon, F. R. and Strodbeck, F. L., (1961). Variations in value orientations, Row, Peterson.

[13] Rokeach, M., (1973). The nature of human values. Free Presse.

[14] Schwartz, S. H., and Bilsky, W. (1987). "Toward a universal psychological structure of human values", Journal of Personality and Social Psychology, 53(3), 550-562.

[15] Schwartz, S. H., (2006). «Les valeurs de base de la personne : théorie, mesures et applications », Revue française de sociologie, (Vol. 47), pages 929 à 968.

[16] Trompenaars, F. and Hampden-Turner, C., (2004). Au-delà du choc des cultures, dépasser les oppositions pour mieux travailler ensemble, Les éditions d'organisation, Paris.

[17] Trompenaars, F, (1993). Riding the waves of culture. Understanding cultural diversity in Business, Nicholas Brealy Publishing, London.

[18] Touba K., (2006). Le travail dans les cultures monothéistes, Le Harmattan, Paris. 